\title{
Resgate da Valorização da Higienização das Mãos em Tempos de Pandemia
}

\author{
Rescuing the Valorization of Hand Hygiene in Times of Pandemic
}

\author{
Sonia Mariza Luiz de Oliveira ${ }^{\mathrm{a}}$; Andressa Veruska Robes ${ }^{\mathrm{a}}$; Janici Therezinha Santos ${ }^{\mathrm{a}}$; Daniela Vieira Amantea ${ }^{\mathrm{a}}$; \\ Paulo Henrique Perlatti D’Alpino*a
}

${ }^{\text {a} U n i v e r s i d a d e ~ A n h a n g u e r a ~ d e ~ S a ̃ o ~ P a u l o, ~ P r o g r a m a ~ d e ~ P o ́ s-G r a d u a c ̧ a ̃ o ~ S t r i c t o ~ S e n s u ~ e m ~ B i o t e c n o l o g i a ~ e ~ I n o v a c ̧ a ̃ o ~ e m ~ S a u ́ d e . ~ S P, ~ B r a s i l . ~}$

*E-mail: paulodalpino@gmail.com

\begin{abstract}
Resumo
A velocidade da disseminação e as alarmantes taxas de mortalidade decorrentes da pandemia do COVID-19 levaram os países a adotarem medidas urgentes para impedir a disseminação do COVID-19. Entre essas se destaca a higienização das mãos, reconhecida como um importante método de prevenção da transmissão de doenças e de cuidados em saúde pública. Trata-se de um procedimento de baixa complexidade e de simples realização. A prática da higienização das mãos é considerada um dos principais mecanismos de combate às infecções relacionadas à assistência na saúde, quer seja em atenção primária ou em níveis de maior complexidade. Além disso, todos deveriam lançar mão da higienização no dia a dia dos afazeres domésticos, especialmente, no cuidado com o núcleo familiar. Apesar disso, sabe-se que há uma baixa adesão à higienização das mãos, sendo que esta prática deveria ser aplicada de maneira consistente. Nesse sentido, propôs-se neste estudo um resgate da valorização da higiene das mãos em tempos de pandemia para o controle de infecções, reforçando a importância da higienização das mãos, enquanto importante prática de prevenção e cuidado.
\end{abstract}

Palavras-chave: Mãos Limpas. Infecção. Higienização. Infecções por Coronavirus.

\begin{abstract}
The dissemination speed and the alarming mortality rates resulting from the COVID-19 pandemic led countries to take urgent measures to prevent the spread of COVID-19. Among them, hand hygiene stands out, recognized as an important method of preventing disease transmission and public health care. It is a low complexity and simple procedure. The hand hygiene practice is considered one of the main mechanisms to fight infections related to health care, whether in primary care or at more complex levels. In addition, everyone should use hygiene in the home care daily routine, especially in caring for the family unit. Despite this, it is known that there is a low adherence to hand hygiene, and this practice should be applied consistently. Therefore, it was proposed in this study to rescue the valorization of hand hygiene in times of pandemic for infection control, reinforcing the importance of hand hygiene as an important prevention and care practice.
\end{abstract}

Keywords: Clean Hands. Infection. Hygiene. Coronavirus Infections.

\section{Introdução}

A epidemia COVID-19 se espalhou atingindo todas as regiões do Mundo com um aumento dramático no número de infectados. A velocidade da disseminação e as alarmantes taxas de mortalidade decorrentes da pandemia levaram os países a adotarem medidas urgentes para impedir a disseminação do COVID-19 (STOLER et al., 2020). A transmissão do COVID-19 ocorre por meio da autoinoculação do vírus em membranas mucosas (nariz, olhos ou boca) e do contato com superfícies contaminadas, o que tem chamado cada vez mais atenção para a necessidade da adoção rápida de medidas preventivas de proteção, a fim de impedir a contaminação entre pessoas (OLIVEIRA, A. et al., 2020; OLIVEIRA, W. et al., 2020). Nesse sentido, a lavagem das mãos é uma das medidas mais importantes, recebendo considerável atenção durante esta pandemia (BRAUER et al., 2020). A higienização das mãos é considerada uma medida de baixo custo e alta efetividade, por serem as mãos o principal veículo de contaminação cruzada (OLIVEIRA, W. et al., 2020). Tratase de uma medida preventiva simples e básica para impedir não somente a disseminação desse vírus, mas também de outros patógenos contagiosos, e que qualquer pessoa pode fazer, frequentemente, de forma independente e autônoma (GOLIN et al., 2020).

Há uma ampla evidência, no entanto, muitos anos antes do avanço da pandemia, de que a lavagem das mãos entre os profissionais de saúde era uma importante questão que necessitava de atenção (ERASMUS et al., 2010; C.D.C., 2019). As mãos são um vetor crítico para a transmissão cruzada de micro-organismos, que ocorre quando se deixa de lavar as mãos de forma eficaz (EDMONDS-WILSON et al., 2015). Nos sistemas e serviços de saúde há campanhas frequentes de conscientização para incentivar a lavagem das mãos entre os profissionais prestadores de serviços de saúde, pacientes e visitantes. Por exemplo, a campanha internacional "Meus cinco momentos para a higiene das mãos" define quais 
os principais momentos, em que profissionais de saúde devem cumprir as regras de higiene ao fazer contato com pacientes ou contaminantes (SAX et al., 2009). No Reino Unido foi lançada uma campanha nacional chamada "Clean your hands" com o objetivo de reduzir os riscos associados às infecções hospitalares por meio do incentivo da higienização eficaz das mãos entre os profissionais de saúde (STONE et al., 2012). Nesta campanha, o lema "Não há problema em pedir" incentiva os pacientes e usuários do sistema público de saúde a pedirem aos profissionais de saúde que lavem as suas mãos (STONE et al., 2012), apoiando o envolvimento dos pacientes para promoverem a lavagem das mãos e trabalharem em conjunto com enfermeiros e outros profissionais de saúde para reduzir a transmissão cruzada de doenças contagiosas (ALZYOOD et al., 2018).

Os cuidados preventivos gerais e, especialmente, a lavagem das mãos, devem ser de responsabilidade de todos. Dessa forma, é recomendável que esforços sejam cada vez maiores para aumentar a conscientização sobre a lavagem das mãos. Considerando-se que a pandemia levou a enormes desafios estruturais para os sistemas de saúde em inúmeros países ao redor do Mundo, houve uma resposta global ao COVID-19 que reconsiderou a necessidade de "voltar ao básico" com relação às estratégias básicas de controle, entre essas a quarentena e isolamento, a lavagem constante das mãos e o distanciamento social (STOLER et al., 2020). De acordo com a Agência Nacional de Vigilância Sanitária - ANVISA (BRASIL, 2009), a higienização das mãos é mundialmente reconhecida como sendo um método de prevenção primária de extrema importância, relacionada ao combate de infecções relacionadas à assistência na saúde, sendo fundamental para o controle e prevenção de infecções, e que englobam as transmissões cruzadas de micro-organismos multirresistentes. Para a Organização Mundial de Saúde (OMS), a prevenção de infecções relacionadas à assistência na saúde só se tornou prioridade a partir do ano 2000 (PITTET et al., 2008). O principal incentivo por parte das autoridades sanitárias e dos órgãos internacionais em relação à lavagem das mãos foi definitivo em função do reconhecimento de sua importância para atingir dois principais objetivos da Organização das Nações Unidas: redução da mortalidade infantil e o combater ao HIV, malária e outras doenças. Mais recentemente, como parte dos requisitos para o desenvolvimento sustentável dos países mais pobres e em desenvolvimento, que é garantir a disponibilidade e o gerenciamento sustentável da água e saneamento para todos, também representaram momentos importantes para considerar a higienização das mãos como um dos principais requisitos para o enfrentamento destas doenças (S.D.G., 2018).

Em que pesem as desigualdades de controle da disseminação do COVID-19, em função das desigualdades socioeconômicas nos diferentes países, é de extrema importância discutir os aspectos relacionados às estratégias de combate à pandemia, que incluem, principalmente, a lavagem das mãos. Dessa forma, o objetivo do presente estudo é reunir conhecimentos básicos sobre o resgate da importância e valorização da higienização das mãos em tempos de pandemia junto à população em geral. Além disso, propõe-se revisar a literatura sobre a lavagem das mãos, especialmente, os tópicos relacionados às propostas dos cuidados básicos de controle de doenças infecciosas, especialmente, considerando o momento atual. O presente estudo objetiva não propriamente esgotar as possibilidades de discussão sobre o assunto, mas estimular a discussão de tópicos mais relevantes sobre como realizar a higienização das mãos de forma eficaz. Nesse sentido, esse resgate da valorização da higienização das mãos em tempos de pandemia será evidenciado se considerando as recomendações da ANVISA e OMS.

\section{Desenvolvimento}

\subsection{Metodologia}

Trata-se de uma discussão sobre o resgate da valorização e importância da higienização das mãos em tempos de pandemia, por meio de um levantamento bibliográfico que aborda aspectos relevantes sobre este tema. Nesse sentido, em coerência com o seu quadro teórico e objetivo, a metodologia do presente estudo discute e propõe uma abordagem organizada em torno da análise de artigos científicos, nas diferentes bases de dados e documentos oficiais governamentais, como o Ministério da Saúde e de organizações internacionais como a OMS. Dessa forma, o presente estudo é uma pesquisa descritiva, qualitativa, de revisão de literatura, que buscou diferentes publicações para melhor compreensão da importância da higienização das mãos, no contexto da pandemia do COVID-19, e sua relevância no sentido de minimizar a velocidade da disseminação e as alarmantes taxas de mortalidade.

Os critérios de inclusão foram artigos científicos, páginas da internet, portarias, resoluções e documentos governamentais e/ou ministeriais publicados no período de 1990 a 2020 e que fazem referência à importância da higienização das mãos, que estivessem relacionadas com o tema a partir dos descritores inseridos no DeCS - Descritores em Ciências da Saúde (http://decs.bvs.br/). Os critérios de exclusão foram: teses, livros, capítulos de livros, anais de congressos ou conferências, relatórios técnicos e científicos. A busca resultou, inicialmente, da leitura do resumo dos artigos encontrados nas diferentes bases de dados, que responderam ao problema da pesquisa, totalizando 58 textos. Destes, foram selecionados 48 documentos e artigos após a leitura do texto completo, se enquadrando nos critérios de inclusão/exclusão.

\subsection{Discussão}

A atenção em saúde pública começou a existir desde o período medieval por meio da criação de instituições para assistências a pessoas carentes, doentes, peregrinos, inválidos e "não doentes". Apesar disso, as primeiras práticas efetivas 
para controle de infecções e medicalização só surgiram com a criação de instituições hospitalares. As práticas para o controle de infecções utilizadas eram de acordo com o conhecimento de enfermidade, que predominava na medicina naquela época (LACERDA; EGRY, 1997).

Em meados do século XVIII, se iniciaram as pesquisas sobre as ocorrências de infecções hospitalares. Por infecção hospitalar se entende a infecção adquirida após a admissão do paciente em uma instituição hospitalar e que se manifeste durante a internação ou após a alta, quando puder ser relacionada com a internação ou procedimentos hospitalares (LACERDA; EGRY, 1997). Nesse contexto, destaca-se a atuação da profissional de Enfermagem Florence Nightingale, que durante a guerra da Criméia (1854), desenvolveu ações com suporte epidemiológico para a prevenção e controle de doenças infecciosas e de infecções hospitalares (FRELLO; CARRARO, 2013). Observou-se que estas práticas resultaram na diminuição das mortes entre combatentes feridos, principalmente, as ocasionadas por infecções. Por sua vez, o médico Ignaz Phillip Semmelweis, com base em sua experiência pessoal, atuou de forma a prevenir e controlar as infecções em um hospital de Viena, particularmente, as infecções puerperais, o que possibilitou identificar fatores causadores destas contaminações (CARRARO, 2004).

Em meados do século XIX, até então de forma impensada, Semmelweis destacou a importância e eficácia da lavagem das mãos, determinando a obrigatoriedade da higienização das mãos para todos os envolvidos nos procedimentos médicos (CARRARO, 2004). Em função de suas descobertas, fundamentais para esta área de conhecimento, foi considerado o "pai do controle de infecções". Além disso, é importante enfatizar a ocorrência de infecções relacionadas à assistência à saúde, que afetam profissionais de saúde que atuam nos hospitais, atendendo doentes com diferentes afecções (FONTANA, 2006). As infecções hospitalares, de forma geral, ocorrem nos hospitais ao redor do mundo, apesar dos esforços que têm sido feitos, especialmente, nos países mais desenvolvidos representam um grande desafio tanto para a saúde pública, afetando doentes e seus familiares que exigem dos profissionais de saúde ações efetivas de prevenção e de controle (BRASIL, 2009). As infecções adquiridas em ambientes de assistência à saúde estão entre as principais causas de morte e aumento de estados de morbidez em doentes hospitalizados (W.H.O., 2005). Nesse sentido, a higienização das mãos é uma das estratégias mais importantes no controle de infecções hospitalares e em saúde pública.

As mãos são consideradas uma das principais ferramentas de trabalho dos profissionais de saúde, e através dessas são realizadas todas as atividades assistenciais. Portanto, nesses serviços de saúde, a segurança do paciente depende de uma higienização cuidadosa e contínua das mãos e respeitando todos os momentos e passos de acordo com uma técnica correta para que seja eficaz. Espera-se que, com a higienização das mãos, sejam removidos micro-organismos que colonizam as camadas superficiais da pele, assim como o suor, a oleosidade e as células mortas, retirando a sujidade propícia à permanência e à proliferação de micro-organismos (ANVISA, 2009). Por higienização das mãos, segundo a ANVISA, pode-se referir a higienização simples das mãos, a higienização antisséptica das mãos, a fricção antisséptica das mãos com preparações alcoólicas e antissepsia cirúrgica das mãos ou, ainda, ao preparo pré-operatório de mãos (ANVISA, 2009). A higienização simples ou básica das mãos se refere à higienização das mãos com água e sabonete comum (ANVISA, 2009). Por outro lado, a higienização antisséptica das mãos é realizada com água e sabonete associado a um agente antisséptico (ANVISA, 2009). A fricção antisséptica das mãos, por sua vez, se refere ao procedimento que consiste em friccionar toda a superfície das mãos com preparação de base alcoólica para reduzir o número de micro-organismos presentes (ANVISA, 2009).

Lavar as mãos com sabão e água por pelo menos 20 segundos ou por meio do uso de desinfetantes à base de álcool para as mãos quando não há água e sabão, é considerada uma primeira linha de defesa para impedir a propagação da pandemia (C.D.C., 2019). As soluções para esfregar as mãos, que contêm álcool, são uma alternativa eficaz à lavagem das mãos com água e sabão (KAMPF, 2018). O emprego destas soluções contendo um percentual alcoólico para esfregar as mãos se mostrou efetivo de acordo com evidências obtidas em epidemias anteriores, que apoiaram a eficácia desta prática (WHO, 2010). No entanto, a dependência destas soluções com percentual alcoólico para esfregar as mãos é menos desejável em comparação com a lavagem das mãos com água e sabão. Isso se deve aos requisitos para produção e distribuição sustentáveis destas soluções para a população em geral, e também aos custos relacionados a sua produção para as populações de baixa renda; deve-se, ainda, considerar as preocupações pelo fato destas soluções serem inflamáveis e, ainda, em função do potencial de envenenamento decorrente da possível ingestão destas soluções (GORMLEY et al., 2012).

A lavagem das mãos com água e sabão pode oferecer proteção mais equitativa e duradoura para proteger a população mais vulnerável da transmissão de doenças diarreicas (WOLF et al., 2018) e infecções respiratórias (RABIE; CURTIS, 2006; MBAKAYA et al., 2017). As desigualdades no acesso à água de abastecimento, saneamento e higiene são reconhecidas há muito tempo como sendo importantes condicionantes, que aumentam a vulnerabilidades às doenças infecciosas preveníveis (PRUSS-USTUN et al., 2019). Além disso, há uma grande preocupação quanto à falta de acesso à água, que pode limitar a lavagem das mãos, em locais de escassez de água, o seu uso é, frequentemente, priorizado para outras tarefas (GEERE et al., 2018). Nesse contexto do impacto global do COVID-19, o acesso limitado à lavagem das mãos afeta grande parte da população mundial e pode minar as estratégias de controle de transmissão da doença. De fato, em 2017, 
estima-se que a dificuldade de acesso à lavagem das mãos seja responsável por $35 \%$ das ocorrências de doenças diarreicas e 9,7\% das infecções respiratórias ao redor do Mundo, afetando a vida de 38,4 milhões de pessoas e causando 707.000 mortes (G.B.D., 2018). Aumentos nestas e em outras causas comuns de morte não relacionadas ao COVID-19 podem também ocorrer em países, em que há enormes problemas sanitários por falta de acesso à água tratada, pois os sistemas de saúde, invariavelmente, ficam sobrecarregados durante a pandemia (BRAUER et al., 2020). Para os locais atualmente sem acesso à água tratada, estratégias alternativas são necessárias e podem ser implementadas em relativamente curto prazo, e ajudariam a reduzir, em longo prazo, um número alarmante de mortes por diarreia e infecções causadoras de doenças respiratórias, que estão diretamente relacionadas à falta do acesso à lavagem das mãos (G.B.D., 2018).

Uma revisão sistemática apontou que, entre as intervenções físicas empregadas para reduzir a transmissão de vírus respiratórios, a lavagem das mãos é o procedimento mais eficaz na redução na transmissão destes vírus de $45 \%$ a 55\% (JEFFERSON et al., 2011). Da mesma forma, uma revisão sistemática sobre a eficácia das medidas de proteção individual na prevenção da transmissão da influenza pandêmica $H 1 \mathrm{~N} 1$, em populações humanas, indicaram uma redução de $38 \%$ na transmissão deste vírus com a lavagem das mãos, enquanto o uso de máscaras pareceu ser a menos eficaz, mesmo com a "etiqueta da tosse" (tossir ou espirrar no antebraço) (SAUNDERS-HASTINGS et al., 2017). Em outra revisão da literatura, também se concluiu que a transmissão da gripe em adultos se mostrou, significativamente, reduzida quando se associou com a lavagem das mãos eficaz (SMITH et al., 2015).

Apesar da importância da higienização das mãos ser enfatizada nos diferentes níveis de assistência à saúde, a adesão a esta prática foi considerada muito baixa nos serviços de saúde, mesmo sendo considerada uma ação simples e a principal medida para redução da disseminação de infecções (COELHO et al., 2011). Inúmeras razões foram relatadas como causas do insucesso e não adesão dos profissionais quanto a esta medida preventiva, como sendo: necessidade de treinamento, motivação, ausência ou pias inadequadas, falta de materiais (sabão, álcool, papel toalha, lixeira), reações cutâneas ao sabonete ou sabão, irresponsabilidade e a falta de tempo em função das inúmeras demandas, entre outros fatores (COELHO et al., 2011). Alguns fatores influenciam para o insucesso da adesão a práticas recomendadas de higienização das mãos, sendo destacadas no Quadro 1.

Quadro 1- Fatores que influenciam no insucesso para adesão da higienização das mãos.

\begin{tabular}{|c|c|c|}
\hline $\begin{array}{c}\text { A. Fatores de risco } \\
\text { observados para } \\
\text { baixa adesão }\end{array}$ & $\begin{array}{c}\text { B. Fatores } \\
\text { relatados } \\
\text { espontaneamente } \\
\text { para a baixa } \\
\text { adesão }\end{array}$ & $\begin{array}{c}\text { C. Barreiras } \\
\text { adicionais } \\
\text { percebidas para } \\
\text { a higienização } \\
\text { adequada das } \\
\text { mãos }\end{array}$ \\
\hline
\end{tabular}

\begin{tabular}{|c|c|c|}
\hline $\begin{array}{l}\text { Trabalho no } \\
\text { tratamento } \\
\text { intensivo }\end{array}$ & $\begin{array}{l}\text { Produtos de } \\
\text { higienização das } \\
\text { mãos provocam } \\
\text { irritações e secura }\end{array}$ & $\begin{array}{l}\text { Falta de } \\
\text { participação ativa } \\
\text { na promoção da } \\
\text { higienização das } \\
\text { mãos em nível } \\
\text { individual ou } \\
\text { institucional } \\
\end{array}$ \\
\hline $\begin{array}{l}\text { Trabalho durante a } \\
\text { semana (em relação } \\
\text { ao final de semana) }\end{array}$ & $\begin{array}{l}\text { Pias estão } \\
\text { localizadas } \\
\text { em locais } \\
\text { inconvenientes ou } \\
\text { faltam pias }\end{array}$ & $\begin{array}{l}\text { Falta de um } \\
\text { modelo padrão para } \\
\text { higienização das } \\
\text { mãos }\end{array}$ \\
\hline $\begin{array}{l}\text { Uso de jalecos e } \\
\text { luvas }\end{array}$ & $\begin{array}{l}\text { Falta de sabão, } \\
\text { papel descartável e } \\
\text { toalha }\end{array}$ & $\begin{array}{l}\text { Falta de prioridade } \\
\text { institucional para } \\
\text { a higienização das } \\
\text { mãos }\end{array}$ \\
\hline Pia automatizada & $\begin{array}{l}\text { Normalmente há } \\
\text { falta de tempo ou a } \\
\text { pressa é grande }\end{array}$ & $\begin{array}{l}\text { Falta de sanção } \\
\text { administrativa a } \\
\text { não cumpridores } \\
\text { das normas/ } \\
\text { recompensa a } \\
\text { cumpridores das } \\
\text { normas } \\
\end{array}$ \\
\hline $\begin{array}{l}\text { Atividades de } \\
\text { alto risco de } \\
\text { contaminação } \\
\text { cruzada }\end{array}$ & $\begin{array}{l}\text { As necessidades } \\
\text { do paciente exigem } \\
\text { prioridade }\end{array}$ & $\begin{array}{l}\text { Falta ambiente } \\
\text { de segurança } \\
\text { institucional }\end{array}$ \\
\hline $\begin{array}{l}\text { Falta ou excesso de } \\
\text { pessoal }\end{array}$ & $\begin{array}{l}\text { A higienização das } \\
\text { mãos interfere no } \\
\text { relacionamento do } \\
\text { profissional com o } \\
\text { paciente }\end{array}$ & $\begin{array}{l}\text { Falta de } \\
\text { valorização dos } \\
\text { profissionais quanto } \\
\text { à importância } \\
\text { da higienização } \\
\text { das mãos } \\
\text { continuamente }\end{array}$ \\
\hline $\begin{array}{l}\text { Alto número de } \\
\text { oportunidades para } \\
\text { higienização das } \\
\text { mãos por hora de } \\
\text { cuidado de doentes }\end{array}$ & $\begin{array}{l}\text { Crença de que o } \\
\text { uso de luvas torna } \\
\text { desnecessária a } \\
\text { higienização das } \\
\text { mãos }\end{array}$ & $\begin{array}{l}\text { Falta de } \\
\text { implementação } \\
\text { de cultura de } \\
\text { segurança na maior } \\
\text { parte dos hospitais, } \\
\text { enfatizando a } 5^{\circ} \\
\text { meta de segurança. }\end{array}$ \\
\hline $\begin{array}{c}\text { A. Fatores de risco } \\
\text { observados para } \\
\text { baixa adesão }\end{array}$ & $\begin{array}{c}\text { B. Fatores } \\
\text { relatados } \\
\text { espontaneamente } \\
\text { para a baixa } \\
\text { adesão }\end{array}$ & $\begin{array}{c}\text { C. Barreiras } \\
\text { adicionais } \\
\text { percebidas para } \\
\text { a higienização } \\
\text { adequada das } \\
\text { mãos } \\
\end{array}$ \\
\hline $\begin{array}{l}\text { Cargo de auxiliar } \\
\text { de enfermagem (em } \\
\text { vez de enfermeiro) }\end{array}$ & $\begin{array}{l}\text { Falta de } \\
\text { conhecimento } \\
\text { de diretrizes } \\
\text { e protocolos / } \\
\text { Sem exemplo } \\
\text { dos colegas e/ou } \\
\text { superiores } \\
\end{array}$ & $\begin{array}{l}\text { Falta de educação } \\
\text { permanente } \\
\text { que enfatize a } \\
\text { higienização das } \\
\text { mãos como técnica } \\
\text { básica e prioritária }\end{array}$ \\
\hline $\begin{array}{l}\text { Cargo de médico } \\
\text { (em vez de } \\
\text { enfermeiro) }\end{array}$ & $\begin{array}{l}\text { Ceticismo } \\
\text { sobre o valor da } \\
\text { higienização das } \\
\text { mãos }\end{array}$ & $\begin{array}{l}\text { Dificuldade de } \\
\text { acesso às pias e } \\
\text { dispensários com } \\
\text { sabão antisséptico e } \\
\text { papel (planta física } \\
\text { precária) }\end{array}$ \\
\hline & $\begin{array}{l}\text { Falta informação } \\
\text { científica sobre o } \\
\text { impacto definitivo } \\
\text { da higienização } \\
\text { das mãos nas } \\
\text { taxas de infecção } \\
\text { relacionadas à } \\
\text { assistência à saúde }\end{array}$ & $\begin{array}{l}\text { Falta de } \\
\text { conscientização } \\
\text { sobre as } \\
\text { possibilidades e } \\
\text { da gravidade da } \\
\text { contaminação } \\
\text { cruzada, } \\
\text { especialmente, nos } \\
\text { ambientes críticos }\end{array}$ \\
\hline
\end{tabular}

Fonte: adaptado de WHO (2005).

A educação em saúde atual tem recebido atenção na pandemia do COVID-19, enfatizando para trabalhadores da 
saúde e público, em geral, as informações relativas à lavagem de mãos (ALZYOOD et al., 2020). A grande diferença em relação a outras epidemias e pandemias anteriores está na disponibilidade dos meios digitais de comunicação que possibilitou, de forma massiva, as informações disseminadas por meio do aplicativo Whatsapp e das redes sociais (KUDCHADKAR; CARROLL, 2020). Vídeos curtos e até mesmo "memes" destinados a mobilizar as pessoas em diferentes dispositivos portáteis, bem como através das mídias sociais, e televisão, rádio, anúncios impressos e outdoors são frequentes, enfatizam a importância da lavagem eficaz das mãos no sentido de impedir a disseminação do COVID-19 (ALZYOOD et al., 2020).

Reportagens diárias nos diferentes meios de comunicação também enfatizam a higienização das mãos considerando que a pandemia não respeita fronteiras e, ainda, o fato de que portadores assintomáticos da doença são potenciais transmissores (GAO et al., 2020). Por outro lado, as dificuldades nos diferentes países em lidar com o surto do COVID-19, muitas vezes, deixam a população sem diretrizes, ficando vulneráveis às notícias falsas ("fake news") e às crises políticas (RIBEIRO; LEIST, 2020).

\subsubsection{Diretrizes sobre a Higienização das Mãos na Prestação de Cuidados de Saúde}

Ainda que a higienização das mãos seja considerada a medida mais importante para prevenir e controlar infecções relacionadas à assistência à saúde, é necessária uma orientação clara, objetiva, eficaz e apropriada sobre as medidas de controle da dispersão de infecções (W.H.O., 2005). A OMS disponibilizou diretrizes sobre a higienização das mãos na assistência à saúde a gestores de hospitais, autoridades e profissionais da saúde, além de informações detalhadas para superar possíveis barreiras, e que devem ser utilizadas, em qualquer situação, em que sejam prestados cuidados de saúde (W.H.O., 2005). Além disso, o Centro de Controle e Prevenção de Doenças (CDC), órgão norte-americano do Departamento de Saúde e Serviços Humanos oferece orientações muito específicas sobre os momentos nos quais se deve realizar a higienização das mãos (C.D.C., 2019). De forma geral, estudos demonstram que a lavagem das mãos deve ocorrer:

- Antes, durante e depois de preparar um alimento;

- Antes de se alimentar;

- Antes e depois de cuidar de alguém em casa que esteja doente com ocorrência de vômitos ou diarreia;

- Antes e depois do tratamento de um corte ou ferimento;

- Depois de usar o banheiro;

- Depois de trocar fraldas ou limpar uma criança que usou o banheiro;

- Depois de assoar o nariz, tossir ou espirrar;

- Depois de tocar em um animal, ração ou resíduo animal;

- Depois de manusear alimentos para animais ou petiscos;

- Depois de tocar no lixo.

Entre os importantes marcos, que contribuíram para a segurança dos pacientes no Brasil, está a criação do Programa
Nacional de Segurança do Paciente - PNS, instituído pela Portaria GM/MS n $529 / 2013$, que objetiva contribuir para a qualificação do cuidado em saúde em todos os estabelecimentos de saúde do território nacional (BRASIL, 2013). Neste programa foi publicada uma resolução da diretoria colegiada (RDC/ANVISA no 36/2013), que instituiu ações para a segurança do paciente em serviços de saúde, que inclui um protocolo de prática de higienização das mãos (ANVISA, 2013). A ANVISA também publicou uma Nota Técnica $n^{\circ}$ 01/2018 com o intuito de orientar gestores e profissionais, que atuam nos serviços de saúde sobre os requisitos básicos e necessários para a seleção de produtos para higienização das mãos em serviços de saúde. Os focos principais desta Nota Técnica são hospitais, unidades de saúde ou clínicas, nos quais o manejo das pessoas, que sofrem com infecções, é constante e, consequentemente, os cuidados devem ser redobrados. Segundo esta Nota Técnica, as mãos devem ser higienizadas com produto apropriado em cinco momentos essenciais: antes de tocar o paciente; antes de realizar procedimento limpo/ asséptico; após risco de exposição a fluidos corporais; após tocar o paciente e após contato com superfícies próximas ao paciente (ANVISA, 2018).

Há diferentes técnicas para higienização das mãos, no entanto, de acordo com a ANVISA, a técnica preconizada é a descrita a seguir (BRASIL, 2009):

I. Abrir a torneira para molhar ambas as mãos, sempre evitando se encostar ao lavatório;

II. Colocar nas palmas das mãos uma porção de sabonete, em forma líquida ou espumosa, cobrindo a face das mesmas;

III. Friccionar uma sobre a outra;

IV. Com a mão esquerda esfregar o dorso da direita, entrelaçando as falanges e repetir o passo na mão oposta;

V. Entrelaçar novamente as falanges e esfregar os espaços interdigitais;

VI. Com a palma da mão oposta se deve friccionar o dorso das falanges segurando-as com movimentação de "vai-evem" e repetir o passo na mão oposta;

VII. Friccionar o polegar com a ajuda da mão esquerda e realizar movimentos circulares e repetir o passo na mão oposta;

VIII. Esfregar as polpas digitais e não se esquecer das unhas, com as mãos em forma de concha realizar movimentos circulares na palma das mãos;

IX. Esfregar também os punhos em movimentos circulares tanto do lado direito como o esquerdo;

X. Para retirar o resquício do sabonete, enxaguar as mãos evitando o contato com o lavatório e a torneira;

XI. Utilizar, se possível, papel toalha descartável para enxugar as mãos, iniciar o processo pelas mãos e descer para os punhos, se por acaso a torneira do lavatório for fechamento manual pegar o papel toalha descartável para poder realizar o fechamento.

Além disso, deve-se enfatizar que a técnica é extremamente importante e é recomendado que todos devessem reservar um tempo mínimo para fazê-lo corretamente. O CDC recomenda 20 segundos de lavagem consistente. Para ajudar a garantir que se passa o tempo correto, o CDC oferece um pequeno truque: cantar "Parabéns para você" por duas vezes, enquanto são lavadas as mãos (C.D.C., 2019). E se sabão e água não 
estiverem prontamente disponíveis, recomenda-se esfregar as mãos por vinte segundos com um desinfetante para as mãos, que contenha pelo menos $60 \%$ de álcool, cobrindo totalmente as mãos. A fricção antisséptica das mãos com preparação de base alcoólica para as mãos não funcionarão, no entanto, se as mesmas estiverem sujas ou oleosas (como, por exemplo, depois de brincar ao ar livre) (C.D.C., 2019). Em um estudo recente (GOLIN et al., 2020), observou-se que utilizar água e sabão para higienização das mãos é o meio mais eficaz para higienizar as mãos em comparação às preparações alcoólicas.

Com o intuito de minimizar e esclarecer dúvidas quanto à higienização das mãos, a UNIFEC publicou, em sua página da internet, perguntas mais comuns e respectivas respostas, que estão descritas a seguir (UNICEF, 2020), que estão resumidas no Quadro 2.

Quadro 2- Perguntas e respostas sobre a higienização das mãos, segundo a UNICEF

\begin{tabular}{|c|c|}
\hline $\begin{array}{l}\text { 1. Como lavo } \\
\text { minhas mãos } \\
\text { corretamente? }\end{array}$ & $\begin{array}{l}\text { Para realizar uma lavagem eficaz das mãos e eliminar todos os vestígios do vírus em suas mãos, deve-se seguir } \\
\text { este passo a passo: } \\
\text { - Etapa 1: molhe as mãos com água corrente } \\
\text { - Etapa 2: aplique sabão suficiente para cobrir as mãos molhadas } \\
\text { - Etapa 3: esfregue todas as superfícies das mãos - incluindo as costas, entre os dedos e as unhas - por pelo } \\
\text { - } \text { Etapos 20 segundos. } \\
\text { - Etapa 5: Seque as mãos com um pano limpo ou toalha de uso único. }\end{array}$ \\
\hline $\begin{array}{l}\text { 2. Por quanto } \\
\text { tempo devo lavar } \\
\text { minhas mãos? }\end{array}$ & $\begin{array}{l}\text { - Você deve lavar as mãos por pelo menos } 20 \text { a } 30 \text { segundos. Uma maneira fácil de cronometrar é cantando } \\
\text { "Parabéns pra você", duas vezes. } \\
\text { - O mesmo vale para o desinfetante para as mãos: use um desinfetante que contenha pelo menos } 60 \% \text { de } \\
\text { álcool e esfregue-o nas mãos por pelo menos } 20 \text { segundos para garantir a cobertura total. }\end{array}$ \\
\hline $\begin{array}{l}\text { 3. Quando devo } \\
\text { lavar minhas } \\
\text { mãos? }\end{array}$ & $\begin{array}{l}\text { Lavar as mãos nos seguintes momentos: } \\
\text { - Depois de assuar o nariz, tossir ou espirrar; } \\
\text { - Depois de visitar um espaço público, incluindo transporte público, mercados e locais de culto; } \\
\text { - Depois de tocar em superfícies fora de casa, incluindo dinheiro; } \\
\text { - Antes, durante e depois de cuidar de uma pessoa doente; } \\
\text { Em geral, deve-se sempre lavar as mãos nos seguintes horários: } \\
\text { - Depois de usar o banheiro; } \\
\text { - Antes e depois de comer; } \\
\text { - Depois de manusear lixo; } \\
\text { - Depois de tocar em animais e animais de estimação; } \\
\text { - Depois de trocar as fraldas dos bebês ou ajudar as crianças a usar o banheiro; }\end{array}$ \\
\hline $\begin{array}{l}\text { o } \\
\text { Iho a } \\
?\end{array}$ & Você pode ajudar as crianças a lavar as mãos, tornando a lavagem das mãos mais fácil e divertida para elas. \\
\hline $\begin{array}{l}\text { 5. Prec } \\
\text { água } n \\
\text { lavar: }\end{array}$ & $\begin{array}{l}\text { Não, você pode usar qualquer temperatura da água para lavar as mãos. Água fria e água morna são igualmente } \\
\text { eficazes para matar germes e vírus - desde que você use sabão! }\end{array}$ \\
\hline $\begin{array}{l}\text { 6. Preciso secar } \\
\text { minhas mãos com } \\
\text { uma toalha? }\end{array}$ & $\begin{array}{l}\text { Os germes se espalham mais facilmente pela pele úmida do que pela pele seca; portanto, secar completamente } \\
\text { as mãos é um passo importante. Toalhas de papel ou panos limpos são a maneira mais eficaz de remover germes } \\
\text { sem espalhá-los para outras superfícies. }\end{array}$ \\
\hline $\begin{array}{l}\text { 7. Qual é o melhor: } \\
\text { lavar as mãos ou } \\
\text { usar desinfetante } \\
\text { para as mãos? }\end{array}$ & $\begin{array}{l}\text { Em geral, a lavagem das mãos com água e sabão e o desinfetante para as mãos, quando praticados / usados } \\
\text { corretamente, são altamente eficazes para matar a maioria dos germes e patógenos. O desinfetante para as mãos } \\
\text { geralmente é mais conveniente quando você está fora de casa, mas pode ser caro ou difícil de encontrar em } \\
\text { contextos de emergência. Além disso, o desinfetante para as mãos à base de álcool mata o Coronavírus, mas } \\
\text { não mata todos os tipos de bactérias e vírus. }\end{array}$ \\
\hline $\begin{array}{l}\text { 8. E se eu n } \\
\text { sabão? }\end{array}$ & $\begin{array}{l}\text { Usar água com cloro ou desinfetante para as mãos que contenha pelo menos } 60 \% \text { de álcool é a melhor segunda } \\
\text { opção se você não tiver sabão e água corrente. Nos casos em que estes não estão disponíveis, o uso de água } \\
\text { com sabão ou cinzas pode ajudar a remover bactérias, embora não com tanta eficácia. Se esses métodos forem } \\
\text { usados, é importante lavar as mãos o mais rápido possível, quando você tiver acesso a instalações de lavagem } \\
\text { de mãos, e, entretanto, evitar o contato com pessoas e superfícies. }\end{array}$ \\
\hline $\begin{array}{l}\text { 9. De que outra } \\
\text { forma posso } \\
\text { ajudar a impedir } \\
\text { a propagação do } \\
\text { Coronavírus? }\end{array}$ & $\begin{array}{l}\text { - Use a etiqueta apropriada para espirros e tosse: cubra a boca e o nariz com um cotovelo ou tecido flexionado } \\
\text { ao tossir ou espirrar, descarte o tecido usado imediatamente e lave as mãos; } \\
\text { - Evite tocar em seu rosto (boca, nariz, olhos); } \\
\text { - Pratique o distanciamento social: evitando apertar as mãos, abraçar ou beijar pessoas, compartilhar } \\
\text { alimentos, utensílios, xícaras e toalhas; } \\
\text { - Evite contato próximo com qualquer pessoa com sintomas de resfriado ou gripe } \\
\text { - Sucure atendimento médico cedo se você ou seu filho tiver febre, tosse ou dificuldade em respirar; } \\
\text { mais frequência (especialmente em espaços públicos). }\end{array}$ \\
\hline
\end{tabular}


No caso do COVID-19, o envolvimento dos profissionais de saúde frente às precauções padrões, como: uso de máscara, óculos, jaleco, higienização das mãos, isolamento social, vem desempenhando um papel fundamental na diminuição da disseminação do vírus. Esta disseminação pode ser, especialmente importante, durante surtos e os ambientes de assistência à saúde podem servir como propagadores de doenças, trazendo impacto tanto nos hospitais quanto na saúde da comunidade. Portanto, torna-se necessário o envolvimento de toda a sociedade e profissionais de saúde no uso consciente das medidas preventivas, especialmente, a higienização correta das mãos para a prevenção e controle da disseminação dos vírus. Logo, a prática de higiene das mãos deve ser valorizada nos serviços de saúde e sociedade como um todo e constitui no procedimento mais eficaz na prevenção e controle de infecções.

O ato simples de higienizar as mãos ainda é um desafio entre os profissionais de saúde e sociedade. Muitos questionamentos são levantados e surgem diversos motivos para o insucesso no ato de lavagem das mãos, entre esses: falta de produtos adequados, incredibilidade sobre a eficácia, tempo dispensado para a realização da técnica. Tais ocorrências pode, de certa forma, se caracterizar negligência por parte dos profissionais. Em função de s epidemias e pandemias vivenciadas durante a evolução da sociedade, tanto os profissionais de saúde quanto a sociedade, em geral, têm se conscientizado sobre a necessidade da higienização das mãos, seja com água e sabão ou por fricção alcoólica. Higienizar as mãos é um ato simples e pode salvar vidas à medida que atua na diminuição da transmissibilidade de micro-organismos patogênicos, controla o índice de infecções cruzadas o que contribui para baixar o índice de óbitos por infecção.

\section{Conclusão}

Ainda que a higienização das mãos seja reconhecida como sendo o meio mais eficaz e com menor custo na redução de velocidade da disseminação e as alarmantes taxas de mortalidade decorrentes da pandemia, observa-se que na prática esse procedimento tão simples é constantemente negligenciado. Diversos motivos são apontados para o insucesso de adesão ao ato simples de higienizar as mãos. No entanto, a falta de motivação das equipes de saúde, além da ausência de um contínuo esclarecimento à população em geral sobre a importância deste tema, de forma geral leva à ausência de comprometimento de todos na adoção de condutas e normas de boas práticas. Nesse sentido, faz-se necessário resgatar a valorização da higienização das mãos.

Vivencia-se hoje a real necessidade de controle de uma pandemia, momento ideal para condução e valorização de medidas de prevenção. É também notória a falta de conhecimento sobre técnicas de controle de infecções, principalmente, no que se refere a simples higienização das mãos: recurso simples, de baixo custo e que salva vidas. Uma vez cessada a pandemia, todos devem continuar promovendo a lavagem das mãos com o mesmo entusiasmo e comprometimento, não apenas na área da saúde, mas também amplamente nas comunidades e nas populações. O crescimento significativo do interesse em promover comportamentos de lavagem das mãos desde o início da pandemia de COVID-19, que deve ser bem aproveitado de forma continuada após a contenção do surto.

\section{Referências}

ALZYOOD, M. et al. COVID-19 reinforces the importance of handwashing. J. Clin. Nurs., 2020.

ALZYOOD, M. et al. An integrative review exploring the perceptions of patients and healthcare professionals towards patient involvement in promoting hand hygiene compliance in the hospital setting. J. Clin. Nurs., v.27, n.7/8, p.1329-1345, 2018.

ANVISA. Segurança do Paciente - Higienização das Mãos Agência Nacional de Vigilância Sanitária, 2009. Disponível em: $<$ http://www.anvisa.gov.br/servicosaude/manuais/paciente_hig maos.pdf $>$.

ANVISA.. Resolução RDC N 36, de 25 de julho de 2013. 2013. Disponível em: < http://bvsms.saude.gov.br/bvs/saudelegis/ anvisa/2013/rdc0036_25_07_2013.html >. Acesso em: 25 jun. 2020.

ANVISA. Nota Técnica No01/2018 GVIMS/GGTES/ ANVISA: Orientações gerais para higiene das mãos em serviços de saúde., 2018. Disponível em: < http:// portal.anvisa.gov.br/documents/33852/271858/ NOTA+T\%C3\%89CNICA+N\%C2\%BA01-2018+GVIMSGGTES-ANVISA/ef1b8e18-a36f-41ae-84c9-53860bc2513f >. Acesso em: 25 jun. 2020.

BRASIL. Segurança do Paciente em Serviços de Saúde: Higienização das Mãos. Brasília: Agência Nacional de Vigilância Sanitária, 2009.

BRASIL Programa Nacional de Segurança do Paciente (PNSP), Portaria $\mathrm{N}^{\circ} 529$, de $1^{\circ}$ de abril de 2013. Disponível em: <http://bvsms. saude.gov.br/bvs/saudelegis/gm/2013/prt0529_01_04_2013.html >. Acesso em: 25 jun. $/ 2020$.

BRAUER, M. et al. Global access to handwashing: implications for COVID-19 control in low-income countries. Environ. Health Perspectives, v.128, n.5, p.57005, 2020.

C.D.C. Hand hygiene in healthcare settings. 2019. Disponível em: $<$ https://www.cdc.gov/handhygiene/index.html $>$. Acesso em: 22 jun. 2020.

CARRARO, T.E. Os postulados de Nightingale e Semmelweis: poder/vital e prevenção/contágio como estratégias para a evitabilidade das infecções. Rev Latinoam. Enferm., v.12, n.4, p.650-657, 2004.

COELHO, M. S.; SILVA ARRUDA, C.; FARIA SIMÕES, S. M. Higienização das mãos como estratégia fundamental no controle de infecção hospitalar: um estudo quantitativo. Rev Eletr. Trim. Enferm., v.21, p.1-12, 2011.

EDMONDS-WILSON, S.L. et al. Review of human hand microbiome research. J. Dermatol. Scie., v. 80, n. 1, p. 3-12, 2015.

ERASMUS, V. et al. Systematic review of studies on compliance with hand hygiene guidelines in hospital care. Infection Control Hosp. Epidemiol., v.31, n.3, p.283-94, 2010.

FONTANA, R.T. As infecções hospitalares e a evolução histórica das infecções. Rev Bras. Enferm., v.59, n.5, p.703-706, 2006.

FRELlO, A.T.; CARRARO, T.E. Contribuições de florence 
nightingale: uma revisão integrativa da literatura. Escola Anna Nery, v.17, n.3, p.573-579, 2013.

G.B.D. Global, regional, and national comparative risk assessment of 84 behavioural, environmental and occupational, and metabolic risks or clusters of risks for 195 countries and territories, 19902017: a systematic analysis for the Global Burden of Disease Study 2017. Lancet, v.392, n.10159, p.1923-1994, 2018.

GEERE, J.-A.L. et al. Is water carriage associated with the water carrier's health? A systematic review of quantitative and qualitative evidence. BMJ Global Health, v.3, n.3, p. e000764, 2018.

GOLIN, A.P.; CHOI, D.; GHAHARY, A. Hand sanitizers: a review of ingredients, mechanisms of action, modes of delivery, and efficacy against coronaviruses. Am. J. Infection Control, 2020.

GORMLEY, N. J. et al. The rising incidence of intentional ingestion of ethanol-containing hand sanitizers. Critical Care Med., v.40, n.1, p.290-294, 2012.

JEFFERSON, T. et al. Physical interventions to interrupt or reduce the spread of respiratory viruses. Cochrane Database Syst. Rev., n.7, 2011.

KAMPF, G. Efficacy of ethanol against viruses in hand disinfection. J. Hosp. Infection, v.98, n.4, p.331-338, 2018.

KUDCHADKAR, S.R.; CARROLL, C.L. Using social media for rapid information dissemination in a pandemic. Pediatric Crit. Care Med., 2020.

LACERDA, R.A.; EGRY, E. Y. As infecções hospitalares e sua relação com o desenvolvimento da assistência hospitalar: reflexões para análise de suas práticas atuais de controle. Rev Latinoam. Enferm., v.5, n.4, p.13-23, 1997.

MBAKAYA, B.C.; LEE, P.H.; LEE, R.L. Hand hygiene intervention strategies to reduce diarrhoea and respiratory infections among schoolchildren in developing countries: a systematic review. Int. J. Environ. Res. Public Health, v.14, n.4, 2017.

OLIVEIRA, A.C.; LUCAS, T.C.; IQUIAPAZA, R.A. What has the covid-19 pandemic taught us about adopting preventive measures? Texto Contexto Enferm., v.29, 2020.

OLIVEIRA, W. K. et al. Como o Brasil pode deter a COVID-19. Epidemiol. Serv. Saúde, v.29, n.2, p.1-8, 2020.

PITTET, D. et al. Infection control as a major World Health Organization priority for developing countries. J. Hosp. Infection, v.68, n.4, p.285-92, 2008.

PRUSS-USTUN, A. et al. Burden of disease from inadequate water, sanitation and hygiene for selected adverse health outcomes: An updated analysis with a focus on low- and middle-income countries. Int. J. Hyg. Environ. Health, v.222, n.5, p.765-777, 2019.
RABIE, T.; CURTIS, V. Handwashing and risk of respiratory infections: a quantitative systematic review. Trop. Med. Int. Health, v.11, n.3, p.258-267, 2006.

S.D.G. Proportion of population with basic handwashing facilities on premises. Sustainable Development Goals - Global Indicator Platform, New York, NY, 2018. Disponível em: < https://sdg. tracking-progress.org/indicator/6-2-1-proportion-of-populationwith-basic-handwashing-facilities-on-premises/ > . Acesso em: 24 jun. 2020.

SAUNDERS-HASTINGS, P. et al. Effectiveness of personal protective measures in reducing pandemic influenza transmission: A systematic review and meta-analysis. Epidemics, v.20, p.1-20, 2017.

SAX, H. et al. The World Health Organization hand hygiene observation method. Am. J. Infec. Control, v. 37, n. 10, p. 827-34, 2009.

SMITH, S.M. et al. Use of non-pharmaceutical interventions to reduce the transmission of influenza in adults: a systematic review. Respirology, v.20, n.6, p.896-903, 2015.

STOLER, J.; JEPSON, W.E.; WUTICH, A. Beyond handwashing: Water insecurity undermines COVID-19 response in developing areas. J. Global Health, v.10, n.1, p.010355, 2020.

STONE, S.P. et al. Evaluation of the national Cleanyourhands campaign to reduce Staphylococcus aureus bacteraemia and Clostridium difficile infection in hospitals in England and Wales by improved hand hygiene: four year, prospective, ecological, interrupted time series study. British Med. J., v.344, p.e3005, 2012.

UNICEF. Everything you need to know about washing your hands to protect against coronavirus (COVID-19). 2020. Disponível em: $<$ https://www.unicef.org/coronavirus/everything-you-need-knowabout-washing-your-hands-protect-against-coronavirus-covid-19 >. Acesso em: 25 jun. 2020.

W.H.O. Diretrizes da OMS sobre higienização das mãos na assistência à saúde. 2005. Disponível em: < www.paho.org/bra/ index.php?option $=$ com_docman $\&$ view $=$ download\&alias $=454-$ diretrizes-as-oms-sobre-higienizacao-das-maos-na-assistencia-asaude-4\&category_slug=seguranca-do-paciente-970\&Itemid=965 >. Acesso em: 24 jun . 2020.

WHO. Guide to local production:WHO-recommended hand rub formulations. 2010. Disponível em: < https://www.who.int/ gpsc/5may/Guide_to_Local_Production.pdf $>$.

WOLF, J. et al. Impact of drinking water, sanitation and handwashing with soap on childhood diarrhoeal disease: updated meta-analysis and meta-regression. Trop. Med. Int. Health, v. 23, n. 5, p. 508-525, 2018. 